\title{
Absence of Specific Histologic Changes in Guinea Pig Skin Treated With Bullous Pemphigoid Antibodies
}

\author{
W. Ray Gammon, M.D., and Robert A. Briggaman, M.D. \\ Department of Dermatology, University of North Carolina, Chapel Hill, North Carolina, U.S.A.
}

Previous studies have reported that intradermal injections of bullous pemphigoid antibodies into guinea pigs can reproduce the histologic and immunohistologic features of bullous pemphigoid lesions. In this study we examined this model to determine its reproducibility and suitability for testing other types of anti-BMZ antibodies. Twenty guinea pigs were injected intradermally with $0.1,0.3$, or $0.5 \mathrm{ml}$ of either bullous pemphigoid serum or IgG fraction containing high-titer complement-binding anti-BMZ antibodies or an equivalent volume of normal human serum or IgG fraction as control. Sites were biopsied at intervals after injection and were examined by routine histology and direct immunofluorescence. The results showed (a) no difference in the incidence of dermal epidermal separation or type of inflammation in experimental and control sites; (b) no evidence of an eosinophil-rich inflammatory reaction typical of bullous pemphigoid; (c) an absence of linear BMZ deposits of IgG and complement in the majority of sites injected with bullous pemphigoid antibodies; and (d) no correlation between dermal-epidermal separation and deposition of immune reactants at the BMZ. These results suggest the histologic changes seen in guinea pigs that are administered intradermal injections of bullous pemphigoid antibodies are nonspecific and that the model is not suitable for testing the pathogenicity of anti-BMZ antibodies in sera or IgG fractions. J Invest Dermatol 90:495-500, 1988

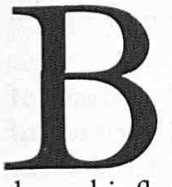

ullous pemphigoid (BP) is an inflammatory subepidermal blistering disease characterized by circulating and tissue-deposited complement- (C) binding autoantibodies to the cutaneous basement membrane zone (BMZ) [1]. The role of "BP antibodies" in the pathogenesis of dermal inflammation and dermal-epidermal separation has been a subject of speculation and investigation since they were initially described in 1965-1967 [2,3]. Studies have provided evidence that the antibodies may be pathogenic, but until recently the evidence was indirect and based on the histologic and immunohistologic features of lesions, studies of complement activity in blister fluids, and the functional interactions between BP antibodies, complements, and leukocytes in vitro.

Recently, more direct evidence was obtained from reports of the successful production of dermal inflammation and dermalepidermal separation in guinea pigs that were administered intradermal injections or BP sera or IgG fractions containing complement-binding BP antibodies [4,5]. At present, the passive transfer model described in these reports is the most compelling evidence in favor of a pathogenic role for BP antibodies and complements in the pathogenesis of the disease.

In this study, we attempted to repeat these experiments to establish the reproducibility of the model and its suitability for studying

Manuscript received June 3, 1987; accepted for publication October 12, 1987

This work was supported by NIH Research Career Development Award AM00956 and NIH grants AM30475 and AM10546.

Reprint requests to: W. Ray Gammon, M.D., Department of Dermatology, 137 North Carolina Memorial Hospital, University of North Carolina School of Medicine, Chapel Hill, North Carolina 27514.

Abbreviations:

BP: bullous pemphigoid

BMZ: basement membrane zone

IgG: immunoglobulin G. the pathogenic role of anti-BMZ antibodies from other blistering diseases.

Out results showed that the intradermal injection of BP sera or IgG fractions containing complement-binding $\mathrm{BP}$ antibodies into guinea pigs could cause dermal inflammation and dermalepidermal separation as previously reported. However, contrary to previous reports, we found that injections of identical volumes of control normal human sera or IgG fractions caused identical histologic changes. The type of inflammatory infiltrate observed in skin injected with BP or normal human sera and IgG fractions was not significantly different and was not the same as that reported in most patients with BP. Immunofluorescent studies of sites injected with BP sera or IgG fractions showed a linear deposition of human IgG or guinea pig $\mathrm{C} 3$ at the $\mathrm{BMZ}$ in the minority of cases and no correlation between deposition of immune reactants and dermalepidermal separation. These results suggest that the histologic changes observed in this model are not specific for BP antibodies and that a convincing in vivo model for the passive transfer of the immunologic and pathologic features of BP lesions in skin remains to be demonstrated.

\section{MATERIALS AND METHODS}

Sera and Immunoglobulin G Fractions Sera were prepared from the blood of four healthy human donors and seven patients with active BP diagnosed by clinical, histologic, and immunohistologic criteria. Blood was drawn into sterile tubes, allowed to clot at room temperature for $1 \mathrm{~h}$ and centrifuged at $400 \mathrm{~g}$. The serum was collected and aliquoted into sterile containers and stored frozen at $-70^{\circ} \mathrm{C}$.

Immunoglobulin $\mathrm{G}$ fractions were prepared from the sera of four patients with BP and one healthy control subject by $40 \%$ ammonium sulfate precipitation and ion exchange chromatography on diethylaminoethyl CL-4B Sepharose (Pharmacia Inc, Piscataway, New Jersey) at $4^{\circ} \mathrm{C}$. The fractions were concentrated at $4^{\circ} \mathrm{C}$ on an Amicon ultrafiltration cell; model M-3 (Amicon Corp., Lexington, Massachusetts) using a YM 100 filter. Analysis of IgG fractions (1 
$\mathrm{mg} / \mathrm{ml}$ ) by agar gel immunodiffusion against antihuman serum revealed a single precipitin arc. Protein concentrations of the IgG fractions were determined by absorbance at OD 280 . The fractions were aliquoted into sterile containers and stored frozen at $-70^{\circ} \mathrm{C}$.

Dilutions of sera and IgG fractions were made using sterile $0.9 \%$ $\mathrm{NaCl}$ buffered with $0.01 \mathrm{M} \mathrm{Na}_{2} \mathrm{HPO}_{4}, 0.01 \mathrm{M} \mathrm{Na} \mathrm{H}_{2} \mathrm{PO}_{4}(\mathrm{pH}$ 7.2) (PBS). Prior to injection, sera and IgG fractions were filtered through a sterile Millex-GS $0.22 \mu \mathrm{m}$ filter (Millipore Corp., Bedford, Massachusetts).

Animals Male Hartley-strain guinea pigs, aged 4-12 mo and weighing 400-600 g, were used in these studies. Before and during the study, all animals were maintained on a normal diet. During the study, animals were kept in separate cages.

Indirect Immunofluorescence Titers of IgG and C3-binding anti-BMZ antibodies were determined by indirect immunofluorescence on $10-\mu \mathrm{m}$-thick cryostat sections of fresh frozen normal human skin using previously described methods and reagents [6]. Antilamina lucida anti-BMZ antibodies were assayed by indirect IgG immunofluorescence using normal skin separated through the lamina lucida as previously described [7].

Passive Transfer Twenty guinea pigs were prepared for injections by clipping the hair from the back and dorsal flanks. Clipped areas were washed with antiseptic soap and the remaining hair removed by shaving with a disposable razor. The animals were then coded with staple-on ear tags.

Injections of BP and control normal human sera or IgG fractions were made at six sites on the left and right dorsal flanks (three sites per flank) in each animal. The sites were arranged parallel to the spine and were separated from each other by a minimum of $3 \mathrm{~cm}$. Injections were made intradermally with a disposable $1.0-\mathrm{ml}$ tuberculin syringe equipped with a 30-gauge needle. All animals were manually restrained by two helpers and injected intradermally with the bevel of the needle down and the syringe held at an angle of $20-30$ degrees to the skin. The sites were marked with indelible ink for future identification.

The injections were 0.1 or $0.5 \mathrm{ml}$ of $\mathrm{BP}$ or control serum, or $0.3 \mathrm{ml}$ of BP or control IgG. In general, each animal received three injections of $\mathrm{BP}$ serum or IgG fraction from a single donor in one flank and three injections of an identical volume of control serum or IgG fraction in the contralateral flank. Two animals received only injections of control normal human serum $(0.5$ or $0.1 \mathrm{ml})$ in all six sites. One animal received no injections but underwent biopsy as described below.

Four-millimeter punch biopsies of injected sites were performed at each of three time intervals $(12,24$, and $48 \mathrm{~h}$ ) after injection. At each interval, a biopsy specimen was obtained from one of the three sites injected with BP serum/IgG fraction and from a site on the opposite flank that had been injected with control serum/IgG fraction. All biopsy specimens were obtained with disposable punches under local anesthesia produced by injecting $0.05-0.1 \mathrm{ml}$. of $1 \%$ xylocaine intradermally approximately $5 \mathrm{~mm}$ from the biopsy site. Xylocaine injections were made using 30 -gauge needles while the animals were held motionless by two helpers.

Each biopsy specimen was immediately bisected and coded. One half of each specimen was processed for routine histology and the others were processed for direct immunofluorescence.

Routine Histology One half of each biopsy specimen was immediately fixed in formalin, mounted in paraffin, and stained with hematoxylin and eosin. Serial sections (a minimum of 20 sections per biopsy) were examined for evidence of dermal - epidermal separation and dermal inflammation. Specimens were scored as positive for dermal-epidermal separation only if separation was seen at sites not adjacent to the specimen edge. The degree of inflammation was graded as 0 , absent; $1+$, minimal; $2+$, moderate; and $3+$, heavy. The types and relative number of inflammatory cells were recorded.

Direct Immunofluorescence One half of each biopsy specimen was immediately frozen in liquid nitrogen, mounted in OCT com-
Table I. Anti-Basement Membrane Zone Antibody Titers and Protein Concentrations in Bullous Pemphigoid and Control Sera and Immunoglobulin G Fractions

\begin{tabular}{cccc}
\hline $\begin{array}{c}\text { Serum/IgG } \\
\text { Fraction }\end{array}$ & IgG Titer & $\begin{array}{c}\text { C3-Binding } \\
\text { Titer }\end{array}$ & $\begin{array}{c}\text { Protein } \\
(\mathrm{mg} / \mathrm{ml})\end{array}$ \\
\hline $\begin{array}{c}\text { BP Sera } \\
\text { Pe }\end{array}$ & 1280 & 160 & - \\
Wa & 1280 & 320 & - \\
Mi & 2560 & 320 & - \\
Sm & 2560 & 640 & - \\
Ly & 2560 & 640 & - \\
Al & 2560 & 160 & - \\
Ro & 1280 & 160 & - \\
BP IgG & 5120 & 320 & 44.0 \\
Wa & 10240 & 640 & 39.4 \\
Ly & 10240 & 320 & 11.0 \\
Al & 1280 & 160 & 27.4 \\
Ro & & & 10.9 \\
NH IgG & 0 & 0 & 16.5 \\
I & 0 & 0 & \\
II & & & \\
\hline
\end{tabular}

pound (ICN Immuno Biologicals, Lisle, Illinois), and stored frozen at $-70^{\circ} \mathrm{C}$ until used. Serial $10-\mu \mathrm{m}$-thick cryostat sections of each biopsy specimen were cut and stained for human $\mathrm{IgG}$ or guinea pig C3 according to previously described methods [6]. Sections were graded as positive if there was linear staining at any point along the BMZ.

Evaluation of Results The results of histologic analysis of dermal-epidermal separation were analyzed separately for each of the three time periods $(12,24$, and $48 \mathrm{~h})$ and each of the three volumes $(0.1,0.3$, and $0.5 \mathrm{ml})$ of serum or $\mathrm{IgG}$ injected.

\section{RESULTS}

Indirect Immunoglobulin $\mathbf{G}$ and Complement-binding Immunofluorescence Titers of IgG and C3-binding anti-BMZ antibodies in the seven BP sera and four BP IgG fractions used in this study are shown in Table I. Titers of IgG anti-BMZ antibodies ranged from $1: 1280$ to $1: 2560$ in sera and from $1: 1280$ to $1: 10,240$ in IgG fractions. Titers of C3-binding anti-BMZ antibodies ranged from $1: 160$ to $1: 640$ in sera and $\operatorname{IgG}$ fractions. No IgG or C3 binding anti-BMZ antibodies were detected in any of the control sera or IgG fractions using either human or guinea pig skin as substrate. Using human skin separated through the lamina lucida as substrate, it was shown that all BP anti-BMZ antibodies bound to the epidermal side of the separation consistent with antilamina lucida antibodies.

Table II. Comparison of Dermal-Epidermal Separation in Guinea Pig Skin Injected with Bullous Pemphigoid and Control Sera and Immunoglobulin G Fractions

\begin{tabular}{lccc}
\hline & & \multicolumn{2}{c}{$\begin{array}{c}\text { Biopsy Specimens with } \\
\text { DES/Total (\%) }\end{array}$} \\
\cline { 3 - 4 } Injection & $\begin{array}{c}\text { Time After } \\
\text { Injection (h) }\end{array}$ & BP & Control \\
\hline $0.5 \mathrm{ml}$ & 12 & $6 / 7(86)$ & $8 / 8(100)$ \\
Serum & 24 & $7 / 8(88)$ & $8 / 9(89)$ \\
& 48 & $2 / 8(25)$ & $1 / 7(14)$ \\
Total & & $15 / 23(65)$ & $17 / 24(71)$ \\
$0.1 \mathrm{ml}$ & 12 & $2 / 3(67)$ & $4 / 6(67)$ \\
Serum & 24 & $2 / 4(50)$ & $3 / 6(50)$ \\
& 48 & $2 / 4(50)$ & $0 / 6(0)$ \\
Total & & $6 / 11(54)$ & $7 / 18(39)$ \\
$0.3 \mathrm{ml}$ & 12 & $2 / 4(50)$ & $3 / 4(75)$ \\
IgG Fraction & 24 & $2 / 4(50)$ & $2 / 4(50)$ \\
& 48 & $5 / 5(100)$ & $3 / 4(75)$ \\
Total & & $9 / 13(69)$ & $8 / 12(67)$ \\
\hline
\end{tabular}


Dermal-Epidermal Separation in Guinea Pig Biopsy Specimens The results of histologic analysis of separation are shown in Table II and Fig 1. In biopsy specimens from sites injected with $0.5 \mathrm{ml}$ of BP serum, 6 of $7(86 \%), 7$ of $8(88 \%)$, and 2 of $8(25 \%)$ showed separation at 12,24 , and $48 \mathrm{~h}$, respectively. In biopsy specimens from sites on the same animals that had been injected with $0.5 \mathrm{ml}$ of control serum, 8 of $8(100 \%), 8$ of $9(89 \%)$, and 1 of 7 $(14 \%)$ showed separation at 12,24 , and $48 \mathrm{~h}$, respectively. When analyzed for all time periods, 15 of $23(65 \%)$ BP-injected sites showed separation and 17 of $24(71 \%)$ control sites showed separation. These differences were not significant.

In biopsy specimens from sites injected with $0.1 \mathrm{ml}$ of $\mathrm{BP}$ or control serum, the results were similar. Sites receiving BP sera showed 2 of $3(67 \%), 2$ of $4(50 \%)$, and 2 of $4(50 \%)$ were separated at 12,24 , and $48 \mathrm{~h}$, respectively. Sites receiving control sera showed 4 of $6(67 \%), 3$ of $6(50 \%)$, and 0 of $6(0 \%)$ were separated at 12,24 , and $48 \mathrm{~h}$, respectively. The number of biopsy specimens from sites injected with BP serum and showing separation for all three time periods ( 6 of $11 ; 54 \%)$, was not significantly greater than those injected with control serum (7 of 18; $39 \%)$.

Similar results were observed when sites were injected with $0.3 \mathrm{ml}$ of IgG fraction. In sites injected with BP IgG, 2 of $4(50 \%), 2$ of $4(50 \%)$, and 5 of $5(100 \%)$ showed separation at 12,24 , and $48 \mathrm{~h}$, respectively. In sites injected with control IgG, 3 of 4 (75\%), 2 of 4
$(50 \%)$, and 3 of $4(75 \%)$ showed separation at 12,24 , and $48 \mathrm{~h}$, respectively. The total number of sites injected with BP IgG fractions that showed separation $(9$ of $13 ; 69 \%)$ was not different from those injected with control $\operatorname{IgG}(67 \%)$.

Two animals that received injections of 0.1 or $0.5 \mathrm{ml}$ of control normal human serum alone showed separation in 10 of 12 injection sites. No separation was observed in six sites from an animal injected only with xylocaine.

Inflammation in Guinea Pig Biopsy Specimens In nearly all biopsy specimens from sites injected with BP or control normal human sera or IgG fractions, there was an inflammatory infiltrate in the mid and upper dermis. Inflammatory cells were present around papillary and upper dermal blood vessels and scattered in the tissue between vessels. In no case were inflammatory cells seen predominantly at the BMZ. The infiltrates ranged from sparse to moderately dense, and they were generally more dense in specimens obtained at 12 and $24 \mathrm{~h}$ rather than in those obtained at $48 \mathrm{~h}$. In most cases, the infiltrate consisted predominantly of mononuclear cells and a few granulocytes. In several specimens there were more granulocytes than mononuclear cells. In some specimens, no granulocytes were seen. In no case were eosinophils the predominant granulocyte in infiltrates. In comparing inflammation between biopsy specimens from sites treated with $\mathrm{BP}$ sera/ $\mathrm{IgG}$ fractions and those treated with
Figure 1. Photomicrographs of hematoxylin and eosin stained sections of guinea pig skin injected with $0.5 \mathrm{ml}$ of BP serum (top frame) or $0.5 \mathrm{ml}$ of normal human serum (bottom frame) $(\times 400)$.
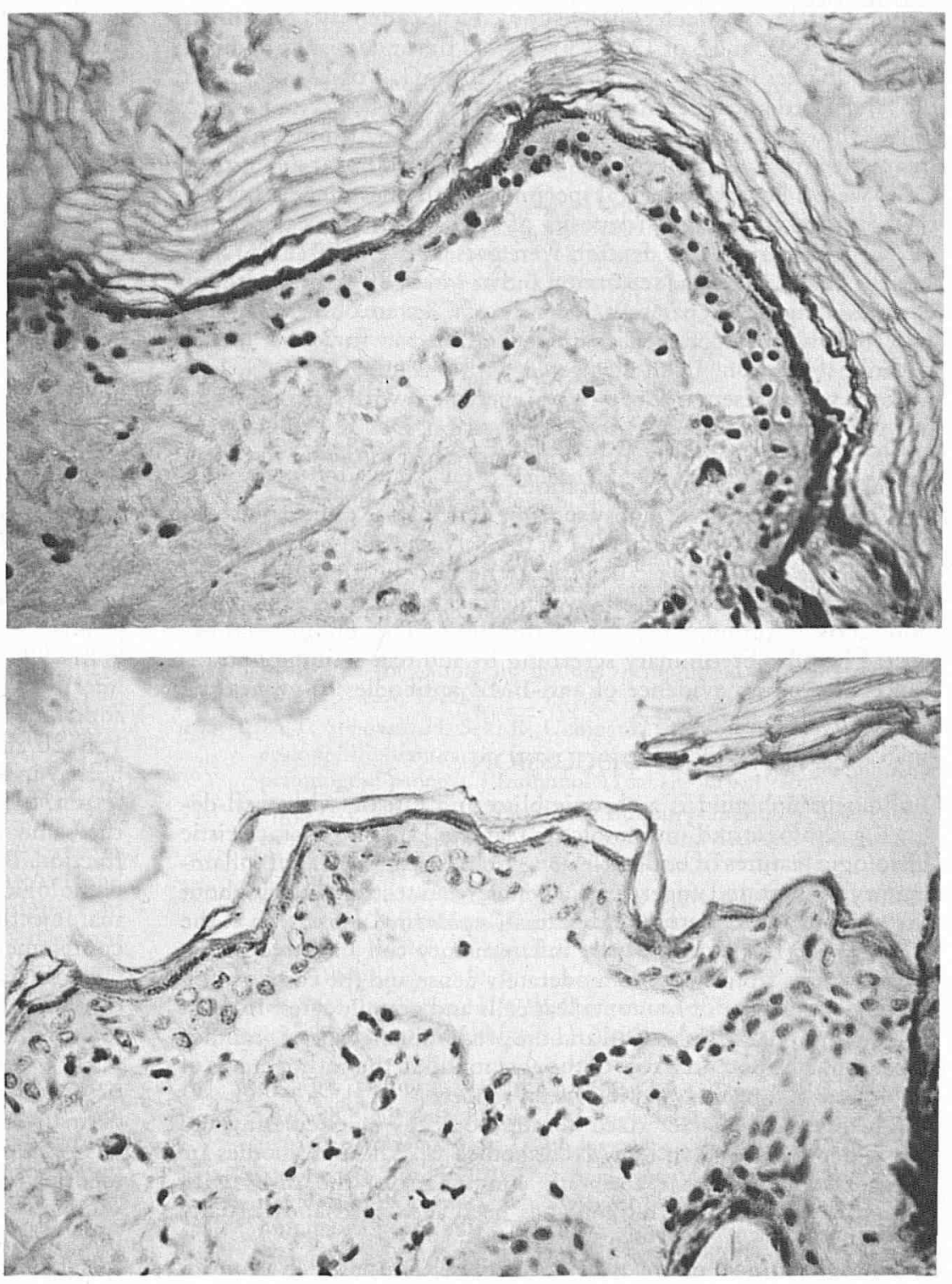
Table III. Linear Basement Membrane Zone Deposits of Human Immunoglobulin G and Guinea Pig C3 in Sites Injected with Complement-Binding Bullous Pemphigoid Antibodies

\begin{tabular}{lccccc}
\hline & \multicolumn{2}{c}{ IgG } & & \multicolumn{2}{c}{ C3 } \\
\cline { 2 - 3 } \cline { 5 - 6 } Sites Injected with & Present & Absent & & Present & Absent \\
\hline 0.5 ml of BP serum & & & & & \\
Bx with DES & 2 & 8 & & 9 \\
Bx without DES & 4 & 1 & & 3 & 4 \\
$\quad$ Total & 6 & 9 & & 5 & 13 \\
0.3 ml of BP IgG & & & & \\
Bx with DES & 2 & 7 & & \\
Bx without DES & 1 & 3 & 3 & 1 \\
$\quad$ Total & 3 & 10 & 7 & 6 \\
\hline
\end{tabular}

control sera/IgG fractions, we could detect no differences in the degree of inflammation, location of inflammatory cells, or types of inflammatory cells in infiltrates.

Results of Direct Immunofluorescent Studies in Guinea Pig Biopsy Specimens Direct immunofluorescence for linear deposits of human IgG and guinea pig $\mathrm{C} 3$ at the $\mathrm{BMZ}$ was performed on skin sites injected with $0.3 \mathrm{ml}$ of $\mathrm{BP} / \mathrm{IgG}$ and $0.5 \mathrm{ml}$ of BP sera. The results are shown in Table III. In sites injected with $0.5 \mathrm{ml} \mathrm{BP}$ serum, 6 of 15 specimens (40\%) showed linear deposits of human IgG at the $\mathrm{BMZ}$ and 5 of $13(38 \%)$ showed linear deposits of guinea pig C3. In sites injected with $0.3 \mathrm{ml}$ of BP IgG, 3 of 13 specimens (23\%) showed linear deposits of human IgG at the BMZ, and 7 of 13 (54\%) showed linear deposits of guinea pig C3. All biopsy specimens with linear deposits of $\mathrm{IgG}$ but one showed linear deposits of $\mathrm{C} 3$ as well. There were several specimens with linear deposits of C3 that did not show linear deposits of IgG. In sites injected with $0.5 \mathrm{ml}$ of BP serum, IgG deposits were present in 2 of $10(20 \%)$ sites with dermal - epidermal separation and in 4 of $5(80 \%)$ sites without dermal-epidermal separation. Deposits of C3 were observed in 2 of $11(18 \%)$ biopsy specimens with separation and in 3 of $7(43 \%)$ without separation. In sites injected with $0.3 \mathrm{ml}$ of $\mathrm{BP}$ IgG, IgG deposits were present in 2 of $9(22 \%)$ specimens with separation and in 1 of $4(25 \%)$ specimens without separation. Deposits of C3 were observed in 4 of $9(44 \%)$ specimens with separation and in 3 of 4 $(75 \%)$ specimens without separation.

We also examined 12 biopsy specimens from two guinea pigs that had been injected with either 0.1 or $0.5 \mathrm{ml}$ of normal human serum for evidence of IgG and C3 deposits at the BMZ. Although 10 of 12 of these biopsy specimens showed dermal-epidermal separation, none showed immune deposits at the BMZ. This finding was expected because preliminary screening by indirect immunofluorescence showed no evidence of anti-BMZ antibodies to guinea pig skin in normal human sera.

\section{DISCUSSION}

Bullous pemphigoid is a chronic blistering disease with well-defined pathologic and immunologic features [1]. The characteristic histologic features of bullous lesions include an infiltrate of inflammatory cells around upper dermal venules and scattered throughout the mid and upper dermis and dermal-epidermal separation at the BMZ $[1,8]$. The extent of the inflammatory cell infiltrate in the dermis varies from sparse to moderately dense and the composition includes a mixture of mononuclear cells and granulocytes. In most cases eosinophils are plentiful and the predominant type of granulocyte seen. The potential role of the eosinophil in the pathogenesis of $\mathrm{BP}$ lesions has been noted in several reports [8-11].

The disease is characterized immunologically by circulating and tissue-deposited IgG anti-BMZ antibodies [1]. These antibodies are autoantibodies, and the antigenic component of the BMZ with which they react (BP antigen) has been identified and partially characterized [12].

Since the initial finding of $\mathrm{BP}$ antibodies, there has been a consid- erable amount of speculation that they may be responsible for lesion formation. The mechanism most often proposed is that the antibodies bind to BP antigen and activate the complement system, thereby leading to complement-mediated inflammation and tissue injury [13].

This hypothesis has gained indirect support by studies showing that multiple components of the complement system are deposited with $\mathrm{BP}$ antibody at the $\mathrm{BMZ}$ in lesional and perilesional skin in nearly $100 \%$ of patients and by studies showing that $50 \%-70 \%$ of patients have circulating anti-BMZ antibodies that can activate complements at the $\mathrm{BMZ}$ in vitro. Additional indirect evidence comes from studies which have reported decreased complement levels, increased levels of degradation products of complement activation, and increased levels of complement-derived chemotactic activity in blister fluids $[14,15]$. Recently it was shown that BP antibodies can activate complement and generate complement-derived mediators that can mediate the recruitment, attachment, and activation of leukocytes at the BMZ of skin sections in vitro [16]. In this in vitro model it was shown that leukocytes attached to the BMZ could cause dermal-epidermal separation [17].

Although the above studies have provided indirect evidence suggesting $\mathrm{BP}$ antibodies may be involved in the pathogenesis of lesions, it has been difficult to demonstrate an effect of these antibodies on skin in vivo. Several early attempts to demonstrate their pathogenicity by intradermal or intravenous injections in monkeys were unsuccessful [18-20]. Although Anhalt et al were successful in demonstrating a pathologic effect of complement-binding BP antibodies after intracorneal injections in rabbits, they were not able to demonstrate histologic or immunohistologic changes when the antibodies were injected intradermally in the same animals [21].

In 1982 and again in 1984, Naito et al reported that the intradermal injection of complement-binding BP antibodies into the shaved backs of guinea pigs resulted in deposition of human $\operatorname{IgG}$ and guinea pig $\mathrm{C} 3$ in a linear pattern at the BMZ, dermal inflammation identical to that reported in BP lesions, and dermal - epidermal separation at the $\mathrm{BMZ}[4,5]$. These changes were observed in skin biopsy specimens that were obtained $6-48 \mathrm{~h}$ after injection of $\mathrm{BP}$ antibodies.

In the first study, they injected $0.5 \mathrm{ml}$ of BP serum, IgG fraction of BP serum, or BP blister fluids that contained BP IgG antibody titers of $1: 320-1: 1280$ and complement-binding titers of $6-8$ [4]. Control sites were injected with the same volume of either normal saline or BP serum that had been pretreated with antihuman IgG. Biopsy specimens were obtained at intervals of between 1 and $48 \mathrm{~h}$ under local xylocaine anesthesia, and pathologic changes typical of BP lesions were observed between 6 and $48 \mathrm{~h}$ in specimens from sites injected with BP sera, IgG fractions, and blister fluids. No changes were described in the control sites.

In 1984, these authors reported similar results from intradermal injections of $0.2 \mathrm{ml}$ of concentrated BP serum or IgG fractions that contained BP IgG and C3-binding antibody titers of 1:640$1: 5120$ and $1: 80-1: 640$, respectively [5]. No changes were reported in specimens from sites injected with unconcentrated BP serum, and only rarely in specimens from control sites injected with the same volume of concentrated normal human serum or $\operatorname{IgG}$ fraction. Based on these two studies, Naito et al concluded that the pathologic changes in guinea pigs that were administered intradermal injections of BP antibodies were specific and BP antibody and complement dependent.

In this study, we used the model described by Naito et al to further examine the ability of BP antibodies to produce the pathological and immunopathological features of BP lesions in guinea pigs. We found that intradermal injections of BP sera or IgG fractions containing complement-binding BP antibodies could cause dermal-epidermal separation that closely resembled BP lesions. When we examined biopsy specimens from sites injected with identical volumes of normal human control sera or IgG fractions, we observed identical pathological changes. This finding suggested that the changes seen in guinea pig skin might not be the result of a specific effect of BP antibodies. 
Several additional observations further support our impression that the pathological changes observed in skin injected with BP antibodies were not specific. If dermal-epidermal separation in these sites had been specific, one might have expected to see some evidence of an antibody dose response. This was not the case. The incidence of dermal-epidermal separation in sites injected with $0.1 \mathrm{ml}$ of BP serum (54\%) was not significantly different from that observed in sites injected with $0.5 \mathrm{ml}(65 \%)$. Another finding that suggests the changes may have been nonspecific was the low incidence of IgG and C3 deposits found at the BMZ. Linear IgG deposits were seen in only $40 \%$ of sites injected with $0.5 \mathrm{ml}$ of BP serum and in only $23 \%$ of those injected with $0.3 \mathrm{ml}$ of BP IgG. Deposits of C3 were found in only 38\% and 54\% of those sites, respectively. An additional finding suggesting the changes were nonspecific was the absence of any correlation between the presence of immune deposits at the BMZ and dermal-epidermal separation. Dermal-epidermal separation was observed in specimens with and without immune deposits and the frequency of separation was no greater in those with deposits than in those without.

It is possible that the low incidence of immune deposits in sites injected with $\mathrm{BP}$ antibodies and the absence of a positive relationship between deposits and separation could be due to destruction of deposits in inflammed tissue; however, we feel this is unlikely. Deposits were absent in about one half of the biopsy specimens in which dermal-epidermal separation did not occur. In these specimens the BMZ appeared completely intact, and in some cases there was no significant inflammatory infiltrate in the upper dermis. Even in those specimens showing dermal-epidermal separation, segments of relatively intact BMZ were usually present; but in most of these, deposits were not observed. We believe that a more likely explanation for the absence of deposits was simply a failure of antibodies to bind in detectable amounts. This hypothesis is supported by recent studies that have shown that much of the BP antigen in viable, intact skin is intracellular and inaccessible to specific antibodies [22-24]. One of those studies has shown that relatively prolonged exposure of viable epidermis to $\mathrm{BP}$ antibodies failed to result in detectable $\mathrm{BMZ}$ binding [22]. With the exception of the studies by Naito et al, the only other passive transfer study that reported binding at the $\mathrm{BMZ}$ was one in which monkeys received massive amounts of transfused BP antibody [20].

A final observation suggesting that dermal - epidermal separation was not specific was the type of inflammation observed in injected sites. Granulocytes were the predominant cell type in only a few cases, and in no case were eosinophils very conspicuous. Furthermore, we saw no evidence indicating a difference in the type of inflammation between experimental and control sites.

Although a specific effect of BP antibodies in causing inflammation and dermal-epidermal separation in this model cannot be excluded, it is clear that it could not be demonstrated because normal human sera and $\mathrm{IgG}$ fractions caused identical pathological changes. It was this finding that differed most from the results reported by Naito et al. In their study, they observed dermal - epidermal separation in only 2 of 96 sites injected with normal human sera or IgG fractions [5]. There were differences between the two studies in the ways in which experimental and control sera and $\mathrm{IgG}$ fractions were prepared and the volumes injected. In their study, sera were concentrated by ultrafiltration to an $\mathrm{IgG}$ concentration of $55.3 \mathrm{mg} / \mathrm{ml}$, and IgG fractions were prepared by affinity purification on protein $\mathrm{A}$. In our study, sera were used without concentration, and IgG fractions were prepared by ion exchange chromatography. In their study, $0.2-\mathrm{ml}$ volumes were injected, and in our study the injected volumes were $0.1,0.3$, and $0.5 \mathrm{ml}$. As the range of volumes used in this study encompassed the volume used in the study by Naito et al, we think it is highly unlikely that differences in injection volume contributed to differences in outcome with control sera.

It seems unlikely that concentrating normal human serum would have made it less likely to cause dermal-epidermal separation, but it is possible that ultrafiltration could have removed or neutralized a serum factor that could cause separation. If that were the case, however, we should not have seen separation in those sites injected with normal human $\operatorname{IgG}$. That material was prepared by ion-exchange chromatography and underwent several dialysis and ultrafiltration steps during preparation. Nevertheless, $67 \%$ of the sites injected with that material showed dermal-epidermal separation.

Based on the findings in this study, we conclude that the pathological changes seen in guinea pig skin after intradermal injection of $\mathrm{BP}$ sera or IgG fractions may be nonspecific and due to factors other than or in addition to BP antibodies. It should be emphasized that the results of this study in no way exclude a role for $\mathrm{BP}$ antibodies and complement in the pathogenesis of BP lesions. However, they do suggest that there are other nonspecific factors present in human sera or IgG fractions or related to the method that can cause clinical and pathological inflammation and dermal-epidermal separation in guinea pigs. In a model such as this, there are numerous factors that alone or in combination might contribute to nonspecific effects. These include mechanical and hydrostatic trauma, phlogistic effects of human serum or IgG fractions, and proteases present in these reagents. Although $\mathrm{BP}$ antibodies may be pathogenic, our results suggest the model used here is not a suitable method for demonstrating it.

\section{REFERENCES}

1. Lever WF: Pemphigus and pemphigoid. J Am Acad Dermatol 1:2-31, 1979.

2. Beutner EH, Lever WF, Witebsky E, Jordon R, Chertock B: Autoantibodies in pemphigus vulgaris; response to an intracellular substance of epidermis. JAMA 192:98-104, 1965.

3. Jordon RE, Beutner EH, Witebsky E, Blumental G, Hale WL, Lever WF: Basement zone antibodies in bullous pemphigoid. JAMA 200:91-96, 1967

4. Naito K, Morioka S, Ogawa H: The pathogenic mechanisms of blister formation in bullous pemphigoid. J Invest Dermatol 79:303-306, 1982.

5. Naito K, Morioka S, Ikeda S, Ogawa H: Experimental bullous pemphigoid in guinea pigs: The role of pemphigoid antibodies, complement and migrating cells. J Invest Dermatol 82:227-230, 1984.

6. Carlo JR, Gammon WR, Sams WM Jr, Ruddy S: Demonstration of the complement regulating protein beta $1 \mathrm{H}$, in skin biopsies from patients with bullous pemphigoid. J Invest Dermatol 73:551 - 553, 1979.

7. Gammon WR, Briggaman RA, Inman AO III, Queen LL, Wheeler CE: Differentiating anti-lamina lucida and anti-sublamina densa anti-BMZ antibodies by indirect immunofluorescence on $1.0 \mathrm{M}$ sodium chloride-separated skin. J Invest Dermatol 82:139-144, 1984.

8. Wintroub BU, Mihan MC Jr, Goetzl EJ, Soter NA, Austen KF: Morphologic and functional evidence for release of mast-cell products in bullous pemphigoid. N Engl J Med 298:417-421, 1978.

9. Dubertret L, Bertaux B, Fosse M, Touraine R: Cellular events leading to blister formation in bullous pemphigoid. $\mathrm{Br} \mathrm{J}$ Dermatol 104:615-624, 1980.

10. Baba T, Sonozaki H, Seki K, Uchigama M, Ikosa Y, Tonisu M: An eosionphil chemctactic factor present in blister fluids of bullous pemphigoid patients. J Immunol 116:112-116, 1976.

11. Varigos GA, Morstyn G, Vadas MA: Bullous pemphigoid blister fluid stimulates eosinophil colony formation and activates eosinophils. Clin Exp Immunol 50:555-562, 1982.

12. Stanley JR, Hawley-Nelson P, Yuspa SH, Shevach EM, Katz SI: Characterization of bullous pemphigoid antigen - a unique basement membrane protein of stratified squamous epithelia. Cell 24:897904, 1981.

13. Sams WM Jr, Gammon WR: Mechanism of lesion production in pemphigus and pemphigoid. J Am Acad Dermatol 6:431-449, 1982 .

14. Jordon RE, Day NK, Sams WM Jr, Good RA: The complement system in bullous pemphigoid. I. Complement and component levels in sera and blister fluids. J Clin Invest 52:1207-1214, 1973.

15. Diaz-Perez JL, Jordon RE: The complement system in bullous pemphigoid. IV. Chemotactic activity in blister fluid. Clin Immuno Immunopathol 5:360 - 370. 1976.

16. Gammon WR, Merritt CC, Lewis DM, Sams WM Jr, Wheeler CE Jr, 
Carlo J: Leukocyte chemotaxis to the dermal epidermal junction of human skin mediated by pemphigoid antibody and complement: Mechanism of cell attachment in the in vitro leukocyte attachment method. J Invest Dermatol 76:514-522, 1981.

17. Gammon WR, Merritt CC, Lewis DM, Sams WM Jr, Carlo JR, Wheeler CE: An in vitro model of immune complex-mediated basement membrane zone separation caused by pemphigoid antibodies, leukocytes and complement. J Invest Dermatol 78:285 - 290, 1982.

18. Holubar K, Chorzelski TP, Gauto M, Beutner EH: Studies in immunodermatology. III. Induction of intraepithelial lesions in monkeys by intramucosal injections of pemphigus antibodies. Int Arch Allergy 44:631-643, 1973.

19. Wood GW, Beutner EH, Chorzelski TP: Studies in immunodermatology. II. Production of pemphigus-like lesions by intradermal injection of monkeys with Brazilian pemphigus foliaceous sera. Int Arch Allergy 42:556-564, 1972.
20. Sams WM Jr, Gleich GJ: Failure to transfer bullous pemphigoid with serum from patients. Proc Soc Exp Biol Med 36:1027-1031, 1971.

21. Anhalt GJ, Bahn CF, Labib RS, Voorhees JJ, Sugar A, Diaz LA: Pathologic effects of bullous pemphigoid autoantibodies on rabbit corneal epithelium. J Clin Invest 68:1097-1101, 1981.

22. Mutasim DF, Takahashi Y, Labib RS, Anhalt GJ, Patel HP, Diaz LA: A pool of pemphigoid antigen(s) is intracellular and associated with the basal cell cytoskeleton-hemidesmosome complex. J Invest Dermatol 84:47-53, 1985.

23. Westgate GE, Weaver AC, Couchman JR: Bullous pemphigoid antigen localization suggests an intracellular association with hemidesmosomes. J Invest Dermatol 84:218-224, 1985.

24. Regnier M, Vaigot P, Michel S, Prunierus M: Localization of bullous pemphigoid antigen (BPA) in isolated human keratinocytes. J Invest Dermatol 85:187-190, 1985. 